\title{
Depressive Symptoms in Women Living in Urban and Rural Environments
}

\author{
Koutsompou Violetta-Irene
}

\begin{abstract}
Depression is a serious mental illness that manifests itself increasingly in recent years. The periods of pregnancy, childbirth and menopause make women more vulnerable both physically and psychologically and can trigger a depressive episode. The new role women have acquired in modern society and the increased responsibilities they carry and in which they must respond bring them stress and depressive mood. The purpose of this research project is to investigate the importance of different aspects in relation to the development of depression in women. More specifically, if they are mothers or not and whether this difference can influence the development of depression, and this, of course, depending on the place of residence (city or province).
\end{abstract}

Index Terms-Depression, place, pregnancy, society, women.

\section{INTRODUCTION}

Depression in women is a gendered mental health problem given that more women than men are likely to experience some form of depression throughout their lifetime. Many factors contribute to the development of depression in women. Many factors also contribute to the ways in which different women perceive and understand the notion of depression and their own experiences that are attributable to depression. It is likely that depression is often undiagnosed or underdiagnosed because women do not attend services where diagnosis occurs or will not fully disclose the nature of their health concerns. Consequently the prevalence, frequency and nature of depression experienced by women worldwide can only be estimated. However, the World Health Organisation [1] has estimated that worldwide, 350 million people may experience depression. It has predicted that depression will be the second most debilitating human condition and contributor to the global burden of disease for all ages and both sexes by 2020 [2]. Women are twice as likely as men to experience depression and approximately $20 \%$ of women, are likely to experience depression at some time in their lives [1]-[4].

Depression varies in its nature, symptoms and severity. The depressed state often features flat affect, loss of interest in usual activities, low self-esteem, difficulties with concentration and remembering, social withdrawal, changes in day to day activities such as eating and sleeping, and feelings of hopelessness. Depression may be experienced as part of Post-Traumatic Stress Disorder or in response to a complicated grieving process. It may be a component of

Manuscript received July 22, 2015; revised October 10, 2015.

Koutsompou Violetta-Irene is with the Psychology Department, University of East London, UK (e-mail: k_violetta120@yahoo.com). bi-polar disorder which can vary in severity amongst people depending upon how well medication is managed and used, or it may be triggered following the birth of a child and range from 'the blues' to severe psychosis.

Measures of depression vary and include self-report through to diagnosis based on the Diagnostic and Statistical Manual [5]. The DSM-IV-TR, its predecessors and formal biomedical diagnostic procedures have been criticised by feminist researchers and practitioners for the medicalisation and pathologising of depression in women that these procedures engender, not only for women themselves, but for community understandings of women's experiences of depression [6], [7]. As Stoppard and Scattolon [8] point out, women do not always have access to, nor wish to access, general practitioners, psychologists and/or psychiatrists who provide such diagnoses and consequent treatment, which often takes the form of medication. Prescription of medication or depression is another gendered phenomenon; medication is more often prescribed for women than it is for men. Further, the DSM provides no insight into gendered differences in the experience or frequency of depression.

\section{SOCIOLOGICAL APPROACHES TO WOMEN AND DEPRESSION}

The concept of social roles has been used to explain why women are more vulnerable to depression than men. But the issue is seen as an issue of social structure rather than addressing the individual's experience of a particular role and the meaning of that role to her. There is evidence, however, that traditional female roles are associated with high prevalence rates of depression in women. This will be considered here in reference to women's roles as mothers and housewives, and the "protective" role of paid employment. The importance of the concept of role will then be considered. Women's risk of depressive symptoms has been found to be higher among mothers with young children [9]-[11], and this may be due to the low social valuation of childcare and mothering. Brown and Harris [12] suggested that women with young children who have no work outside the home are particularly vulnerable to depression and that, following the work of Oakley [13] on women's experiences of childcare and housework, this may be due to the low social status accorded to childcare and housework. Following the work of Gavron [14] who suggested that women with young children felt both trapped and undervalued in their work in the home, Brown and Harris [12] argued that the low social value and recognition of women's roles as wives and mothers may be a causal factor in depression, linked with the occurrence of low self-esteem. 
Depression has been associated with women's roles as housewives, as in 'the noxious nature of the housewife role' theory of depression [15]. It is not clear what the basis of the association is, though Repetti and Crosby [15] found that high levels of dissatisfaction were related to higher levels of depression for housewives than any other occupational or family status group. But this also seems to depend on the quality of the woman's experience, since the extent to which being a housewife is related to depression depends on the social status of the couple and the quality of their marriage. One possible explanation may be that wealthier wives could hire others to perform household tasks and themselves participate in more activities outside the home [15].

There is also evidence that levels of depression in housewives may be linked to the quality of their relationship with their husband. Vanfossen [16] found that among housewives there was a significant relationship between levels of depression and the affirmation received from their spouse and the level of intimacy in the marriage, and that women whose husbands shared the housework were less likely to be depressed. Brown and Harris [12] identify the lack of a supportive partner and the absence of paid work outside the home as vulnerability factors for depression in women.

The above evidence may suggest that depression can be protected against by employment outside the home, or multiple roles. Theories explaining vulnerability in terms of social roles also suggest that individual identity may be constructed through the performance of several roles, and that this may be protective against depression. Thus Thoits [17] chas argued that individuals who have several roles are protected from depression. However Gove and Tudor [18] argue that while a single role as a housewife may lead to few sources of gratification and be associated with depression, women who work and have a husband and children or both may be also vulnerable to stress because of role overload and that this may be associated with depression. Women who both work and have a family are expected to carry out two full-time jobs, and these may have opposing demands: to be patient, self sacrificing and supportive at home and self-sufficient, aggressive and achievement oriented at work [19].

Women who have no children may also be vulnerable to depression, through their roles at work. Their identity as women may be challenged and there is evidence thatinfertility can be associated with feelings of failure and depression [20], [21]. In addition, women are likely to be undervalued at work: historically this has occurred through legalised sex discrimination [22], whereas now it occurs through institutionalised practices which, though more subtle, may still carry the same message and hence be more difficult to identify and act against. Women are likely to work in lower status and poorly paid jobs, associated with traditional female qualities of servicing and caring for others, and where they do work in professional posts are unlikely to achieve promotion as rapidly or be paid as well as their male peers [23].

The evidence from multiple role theory also suggests that women's experiences may be variable between roles and that this may be a source of both protection and vulnerability to depression. What may be at issue is the quality of roles and status rather than the occupancy of particular roles and status [24], which points against the need to look at meaning through analysing women's own accounts of their experiences.

\section{MOTHERHOOD}

Being a mother determines a woman's personal and social identity [25] but it also determines a woman's identity whether or not she has children.

Motherhood can be seen as intrinsic to womanhood [25]. Studies of adolescent girls suggest that motherhood and marriage may be part of gender socialisation. Hazel Beckett [26] and Chris Griffin [27], [28] both found that motherhood and marriage are seen as eventual and inevitable aims among school leavers. Beckett [26] found that young women saw a combination of marriage, motherhood and a career as non-problematic, and that the greater choice of occupation available to women has led to greater flexibility. However, motherhood was still seen as central and neither was it seen as preventing a career nor was a career seen as an alternative and equally acceptable choice to motherhood. Griffin [28] suggested that few choices were available to young, working class women in terms of employment, and that motherhood was both the most easily available choice and potentially the most well rewarded choice. Sharpe [29] identified ways in which cultural stereotyping was used to identify ideal and typical characteristics of women, among Afro-Caribbean, Asian and White girls living in London. She suggested that the cultural stereotype of motherhood with which girls were presented, and on which they based their own expectations, was an idealized image but one which they accepted despite the evidence presented in their own mothers' experiences. The idealised version includes fulfilment, satisfaction, relative freedom and adult status.

Part of the explanation for the power of the ideal may be the poor alternative options available to some women within paid employment or unemployment. But it may also be that motherhood is a powerful ideal, not just because it is the best available option but because it represents the only potential opportunity to achieve relative autonomy. This potential may override the low social status of motherhood, since motherhood is portrayed as both a private and domestic experience and implicitly as a way of escaping 'the public sphere, and thus it may be seen by some women as a positive opportunity to achieve some autonomy. Motherhood is therefore not so much a choice but an assumption around which other choices are made. It is an experience into which women are socialised as part of their identity as women, and hence something which they may not consciously consider as an option which they may or may not take. While women may apparently choose to have children, very often they may simply not fail to chose not to have children and on an unconscious level may accept childbearing not in terms of a positive choice but as something inevitable. Moreover, although motherhood affects identity it is also built into every woman's identity whether or not she has children, and is problematic in terms of a choice not to have children as well as the actual experience when a woman does have children. Socialisation into the female role equates marriage and 
motherhood with femininity, and women may see themselves as defective women if they fail to do both. Motherhood may be seen as the achievement of adult feminine status [30]. Women who do not have children may be seen as inadequate women.

\section{THE IMPORTANCE OF ENVIRONMENT-URBAN AND RURAL DIFFERENCES IN MENTAL DISORDERS}

Despite the general health advantage of city dwellers, incidence (the rate at which new disease events occur in a population) and prevalence (the number of events, e.g., a given disease, in a given population at a designated time) of specific mental disorders seem to be increased in this population. Meta-analytic studies report that among individuals living in cities, the prevalence of all psychiatric disorders is increased by $38 \%$, of mood disorders by $39 \%$, and of anxiety disorders by $21 \%$, as compared to inhabitants of rural areas [31]. Adjustment for potential confounders like age, gender, marital status, social class or ethnicity had limited impact on these findings, indicating that these population characteristics do not substantially contribute to the observed disparities. During evolution, processing and performing complex social interaction emerged as a key factor driving the development of larger brains in primates and humans [32].Social skills that are necessary for profiting from diversification of knowledge, for refining commercial relationships or for building tactical alliances in order to expand power, substantially contributed to the success of the human species. A supportive social environment turned out as one of the most important conditions necessary for mental and physical health. Therefore, acute loss of group support may be perceived as fundamental threat, eliciting a stress reaction comparable to acute physical endangerment [33]. But also more chronic forms of social stress are of interest, as exposure to a socially stressful environment often expands over a period of weeks, months or years. For example, long-lasting social isolation has a considerable impact on both physical and mental health, as it is associated with an increased risk of depression, anxiety, coronary heart disease, and death [34]. The impact of social stress as a risk factor for both mental and physical disease is corroborated by findings that highlight the beneficial impact of social support. This factor emerged as a powerful resource to mitigate the effects of acute stress [35]. Finally, the presence of this factor is associated with a reduction of mortality exceeding the influence of physical activity, smoking cessation and lower body-mass index [36]. Stress research, neuroscience and epidemiology have substantially contributed to elucidate the role of social stress as a risk factor for mental disorders. Stress research has identified potent ingredients of acute social stress. Exposure to tasks that were uncontrollable and included social threat, i.e. failure in front of significant others were associated with the most profound activation of the endocrine stress response [37]. Pathways through which stress exposure increases the risk of disease manifestation have been investigated in most major mental disorders. They vary according to type of stressor, exposure time and subject characteristics. In 1997, Walker and Diforio [38] proposed the "neural diathesis-stress model", and suggested that the interaction of specific genetic and environmental factors resulted in increased stress system activation, thus facilitating onset, exacerbation and relapse of schizophrenia. According to this model, stressful events are associated with an abnormal activity of the hypothalamic-pituitaryadrenal (HPA) axis, triggering a cascade of events leading to dysfunction of dopaminergic neurotransmission and neural circuits relevant for psychosis symptom generation [39]. Significant stress-associated dopamine release in the ventral striatum in healthy volunteers [40] and stress-responsive system dysfunction in schizophrenic patients upon exposure of to an experimental social stressor both support this hypothesis. Furthermore, prolonged exposure to stress seems to be capable of inducing architectural changes in specific brain areas such as the prefrontal cortex which mediates the highest-order cognitive abilities. Chronic stress was also found to be associated with a decrease in volume in of the hippocampus, a structure central to memory storage and retrieval [41]. Interestingly, the hippocampus is also involved in HPA system regulation, as this structure exerts a tonic inhibition on stress system activity, which subsides with stress exposure. Through this mechanism, hippocampal damage may result in enduring HPA system overactivity, further aggravating damage to brain structures via prolonged cortisol exposure. Neuroscience has made substantial progress in exploring the neural circuits that support social function and process social stress. Segmentation of social cognition differentiates social perception, attribution and categorization. During these processes, social stimuli that arise from other group members are detected and analysed, and behaviour is interpreted as indicating a specific mental state [42]. The emotional and motivational appraisal of social stimuli is processed in a neural mutually interacting circuit involving the brain regions amygdala, insulate, subgenual anterior cingulate cortex (ACC) as well as the orbitofrontal cortex. This circuit closely interacts with the brain structures that direct the stress-responsive systems including the HPA system. The smooth functioning of these neural circuits may be endangered by genetic and environmental factors. Several lines of evidence indicate that the maturing brain is vulnerable to environmental stressors especially in genetically predisposed subjects [43]. For example, the action of the hypothalamic neuropeptides oxytocin and vasopressin differs in carriers of genetic variants encoding the receptor for these molecules [44], [45]. Exposure to social stress is associated with a profound effect on these receptors, affecting function and structure of hypothalamic-limbic circuits.

\section{A. Perspective}

The goal of understanding how social stress acts as a risk factor for mental disorders in urban populations may be pursued on $\mathrm{N}$ several levels. Effects of infrastructure (population density, access to green space), economic issues (rates of employment, working conditions), environmental pollutants (air pollution, noise, toxins, light) and social conditions (social coherence, density of social networks) need to be considered and weighted in order to identify the most potent contributors to social stress. Vice versa, it should not be missed to have a closer look at probably protective 
factors of the rural environment. Better education, higher employment and easier access to health care have been identified as factors contributing to improved health in cities, but these factors have to be actively created and maintained through policy interventions [46]. Investigations aimed at a better understanding of social stress in the urban environment should have a high spatial resolution, combing tools from different fields like epidemiology, environmental science, social sciences, and medicine. Tools are available for measuring size and complexity of social networks, perceived social standing, subjective stress level, major life events, and others [47]. Increasingly, cross-sectional studies with single time points of observation are replaced by studies focusing the daily flow of life and longitudinal observations of cohorts, often starting with birth or young age. Also, it has been successful to probe hypotheses on neural social stress processing by applying major factors which contribute to the increased risk for mental illness in urban environments might not only give valuable insights into etiological aspects of mental disorders but also inform policy makers about relevant health risks of one of our most important environments [48].

TABLE I: MEAN AND STANDARD DEVIATION OF DEPRESSION OF THE SAMPLE

\begin{tabular}{|c|c|c|c|c|c|}
\hline & $\mathrm{N}$ & Minimum & Maximum & Mean & Std. Deviation \\
\hline Depression & 100 &, 00 & 21,00 & 11,69 & 5,31 \\
& & & & & \\
\hline
\end{tabular}

\section{RESEARCH METHODOLOGY}

This research is a comparative quantitative study. Since there is no corresponding research study on this issue in Greece the aim of this investigation is to explore the importance of different aspects in relation to the development of depression. In particular, it has been examined the percentage of women living in urban centers and in the provinces as well as the role of motherhood and its relationship with the development of the disease are discussed in this research work.

TABLE II: MEANS AND STANDARD DEVIATIONS OF DEPRESSION IN WOMEN WITH AND WITHOUT CHILDREN LIVING IN RURAL AND URBAN

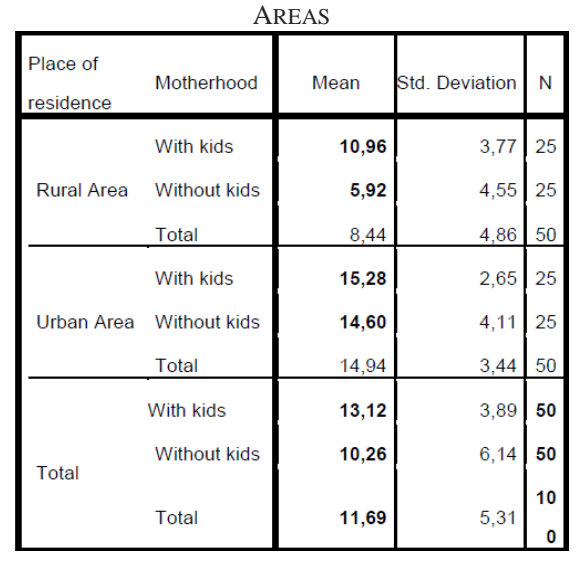

\section{THE PARTICIPANTS}

The sample was selected randomly, questionnaires were given to Greek women in various rural areas and in three urban centers in Greece, and particularly questionnaires were distributed in Athens, Thessaloniki and Lamia. The sample consists of a total of 100 people, namely 50 women living in the city and 50 respectively who live in the province of those 25 in each sample are mothers and the others are not. Women are between the ages of 20-45. To join in the research, they were informed verbally about the subject of the study and signed the corresponding consent form while respecting the confidentiality of their personal data. Their participation in the survey is voluntary. The participants are not diagnosed with earlier psychiatric or mental disorder.

\section{PSYCHOMETRIC TOOLS}

The Hospital Anxiety and Depression Scale (HADS), a self-assessment scale, was developed to detect states of depression, anxiety and emotional distress amongst patients who were being treated for a variety of clinical problems [49]. The purpose of its creation was to offer clinicians a practical, user friendly and reliable tool for the recognition of anxiety and depression. The role of the scale is more than diagnostic scanning.

The HADS is a scale which is completed by the test and comprises 14 entries, each of which has four possible responses (0-3). It is designed to assess anxiety (HADS-A) and depression (HADS-D) (7 entries for each state, with ranges from 0-21). We used the Greek translation of the scale and only measured the rate of depression.

\section{RESULTS}

Statistical analysis was performed using SPSS 17.0 total questionnaires completed specifically in Table II, the mean and the standard deviation of the total sample.

The analysis in Table II shows that the rates of depression in mothers living in rural area $(M=10.96)$ and those living in cities $(M=15.28)$ are close enough. Comparing the averages of women, both those who are not mothers and living in the province $(M=5.92)$ and equivalent to those living in city ( $M$ $=14.60)$ notes that although close enough, women without children have a lower rate.

Table III shows the overall analysis which was applied to examine the differences between the residence and motherhood in relation to the emergence of depression. Found statistical significance in the region and maternity interaction $(\mathrm{F}(1,96)=8,07, p<, 01)$. Also, found statistically significance main effect of residence $(\mathrm{F}(1,96)=71,72, p$ $<0,001)$ and motherhood $(\mathrm{F}(1,96)=13,88, p<0.001)$.

\section{DISCUSSION}

The study conducted found that the onset of depression seems to affect positively the variables examined here which are residence and motherhood. It has also found the existence of correlation between the two variables and relative interaction in the appearance of depression. The findings of this research are confirmed by the international research activity as shown in a study of Glavin K., Smith L., \& Sorum 
R. [50], where estimating the prevalence in two provinces of Norway, with 2227 women recorded that ranged over from 9 to $14.4 \%$. Data from the World Health Organization record the incidence of depression and anxiety is about $8-10 \%$ during pregnancy and $13 \%$ after birth [2].

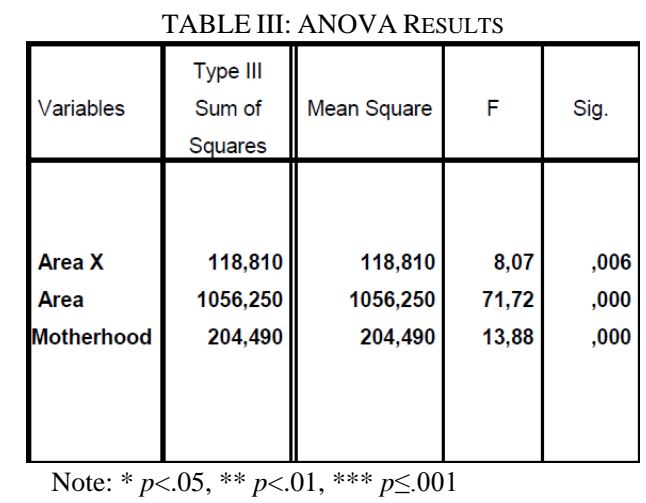

There is, therefore, significant effect of two independent variables in the occurrence of depression as well as the fact that the combination of these two factors seem to be "responsible" for the high level of depression. The data is confirmed by the existing literature to the effect that there is a correlation between social anxiety and mental disorder in urban populations [50]. A major characteristic of the result of this research is that women who live in large urban centers seem to incur more emotionally and eventually develop depression as opposed to those living in the province; even though the second category has a relatively high average. Thus, it is be less than with the city category itself. In the literature, it has been found that in the provincial centers, where life flows more simply and slowly, people living in a healthier environment (close to nature) seems not to have the same disorder incidence rates since the general framework functions as protective factor [50], [51]. Additionally, through the findings reported in meta-analytical studies recorded that among people living in cities, the prevalence of all psychiatric disorders increased by $38 \%$, of mood disorders by $39 \%$, and anxiety disorders by $21 \%$ compared with residents of rural areas [52].

\section{LiMitATiOnS}

Like any research study this one has disadvantages and limitations. In this work, it should be collected larger and more representative sample of the general population in order to achieve results and that would have greater significance and which could be expanded for the general female population in Greece. Nevertheless, the positive of this research study is hath it is both a prospective study and that it is a survey for the first time in Greek population; it had not been preceded some corresponding study in the field to the local population and thus it received strong interest on the part of all women who were given the questionnaire especially by mothers who participated enthusiastically and willingly. Another key advantage which should be mentioned here is that the HADS questionnaire is small in size so women they did not get tired and had adequate time to complete it without resent.

\section{RECOMMENDATIONS}

Further research is needed to confirm or disprove the results of this study. Of particular interest would be to explore data specifying etiological factors for depression such as the economic crisis, the role of the relationship of the woman with the partner and the role it plays regarding family, pregnancy, motherhood.

At the same time, it would be useful to investigate the effect of environmental reports which could aggravate or cause disturbance. Also, a simultaneous study of stress would put another piece in the puzzle of depression, for example, a research regarding stress, which holds a key part of everyday life of all women and particularly young mothers, useful information would be raised from open-ended questions where women could complement those factors which cause her stress and psychological transition after the baby is born and especially if she feels emotionally and financially independent to raise the child as well as to develop herself.

\section{CONCLUSION}

Early detection of depression is essential to prevent complications both individually and collectively. In conclusion, it should be said that mental health, particularly depression is an issue which requires special attention not only to prevent but also to avoid the adverse repercussions of that. The data of this study could be compared with the respective international and national studies to redefine the objectives need to be achieved and the methods to be used in order to promote mental health of women as they form an important link in the chain of society and health promotion if, among other things, they are holding another key and vital role, that of the mother. This is a complex issue and necessary handlings should be done for the improvement and quality of life of the female population and its environment. It is hoped that other research studies will broaden the perspective and add their own bit in this complex and frequent mood disorder.

\section{REFERENCES}

[1] World Health Organisation Depression: Fact Sheet no. 369, World Health Organisation, Geneva, 2012.

[2] World Health Organisation Depression: World Health Organisation, World Health Organisation, Geneva, 2009.

[3] C. Kuehner, "Gender differences in unipolar depression: An update of epidemiological findings and possible explanations," Acta Psychiatr Scand 108, pp. 163-174, 2003.

[4] J. Ussher, "Are we medicalising women's misery? A critical review of women's higher rates of reported depression," Feminism Psychol, vol. 20, no. 1, pp. 9-35, 2010.

[5] American Psychiatric Association, Diagnostic and Statistical Manual of Mental Disorders (4th ed., text rev.).,Washington, DC. 2000.

[6] K. Eriksen and V. Kress, "Gender and diagnosis: Struggles and suggestions for counsellors," J Couns Dev, vol. 86, pp. 152-162, 2008.

[7] J. Marecek, "Social suffering, gender, and women's depression," in C. Keyes and S. Goodman eds, Women and Depression: A Handbook for the Social, Behavioural and Biomedical Sciences, Cambridge University Press, Cambridge, 2006

[8] J. Stoppard and Y. Scattolon, "Getting on with life: Women'S experiences and ways of coping with depression," Can Psychol, vol. 40, no. 2, p. 205, 1999.

[9] G. W. Brown, M. N. Bhrolcháin, and T. Harris, "Social class and psychiatric disturbance among women in an urban population," Sociology, vol. 9, pp. 225-254, 1975.

[10] L. Perlin and J. Johnson, "Marital status, life strains and depression," American Sociological Review, vol. 42, pp. 57-70, 1977. 
[11] L. S. Radloff, "Sex differences in depression: The effects of occupation and marital status," Sex Roles, vol. 1, pp. 249-265, 1975.

[12] G. W. Brown and T. Harris, Social Origins of Depression. A Study of Psychiatric Disorder in Women, London: Tavistock. Reprinted 1989, London: Routledge, 1978.

[13] A. Oakley, "Wise woman and medicine man: Changes in the management of childbirth," The Rights and Wrongs of Women, Harmondsworth: Penguin, 1976.

[14] H. Gavron, The Captive Wife, Harmondsworth: Penguin, 1966

[15] R. L. Repeti and F. Crosby, "Women and depression: Exploring the adult role explanation," Journal of Social and Clinical Psychology, vol. 2, no. 1, pp. 57-70, 1984.

[16] B. E. Vanfossen, "Sex differences in the mental healtheffects of spouse support and equality," Journal of Health and Social Behaviour, vol. 22, pp. 130-143, 1981

[17] P. A. Thoits, "Multiple identities: Examining gender and marital status in distress," American Sociological Review, vol. 51, pp. 259-272, 1986.

[18] W. R. Gove and J. F. Tudor, "Adult sex role and mental illness," American Journal of Sociology, vol. 78, pp. 812-835, 1973.

[19] S. Nolen-Hoeksema, Sex Differences in Depression, Stanford, Calif: Stanford University Press, 1990.

[20] A. Woollett, "Why motherhood is popular: An analysis of accounts of mothers and childless women," presented at the Second Women in Psychology Conference at Brunel University, Uxhridge, 1987.

[21] B. Ehrenreich and D. English, For her Own Good: 150 Years of the Experts Advice to Women, London: Pluto Press, 1978.

[22] S. Faludi, Backlash, London: Viking, 1992.

[23] E. McGarth, Women and Depression: Risk Factors and Treatment Issues: Final Report of the American Psychological Association Task Force on Women and Depression, Washington: APA, 1990.

[24] P. Nicolson, The Social Psychology of Post Natal Depression, Unpublished Ph.D. Thesis, University of London, 1988.

[25] P. Nicolson, "Motherhood and women's lives," in Introducing Women's Studies, D. Richardson and V. Robinson, (Eds.) Basingstoke: Macmillan, 1993b.

[26] H. Beckett, "Adolescent identity development," in Feminist Social Psychology: Developing Theory and Practice, S. Wilkinson, (Ed.) Milton Keynes: Open University Press, 1986.

[27] C. Griffin, "Qualitative methods and female experience: Young women from school to the job market," in Psychology: Developing Theory and Practice Feminist Social, S. Wilkinson (Ed.) Milton Keynes: Open University Press, 1986

[28] C. Griffin, "I'm not a women's libber hut..." Feminism, consciousness and identity," in The Social Identity of Women, S. Skevington and D. Baker, (Eds.), London: Sage, 1989.

[29] S. Sharpe, Just Like a Girl: How Girls Learn to be Women, Penguin, 1976.

[30] A. Woollett, "The psychology of infertility and infertility investigations," in The Psychology of Women's Health and Health Care P. Nicolson and J.M. Ussher, (Eds.) London: Macmillan, 1992.

[31] J. Peen, R. A. Schoevers, A. T. Beekman, and J. Dekker, The Current Status of Urbanrural Differences in Psychiatric Disorders, Acta Psychiatrica Scandinavica, vol. 121, 2010.

[32] R. I. Dunbar and S. Shultz, "Evolution in the social Brain," Science, vol. 317, pp. 1344-1347, 2007.

[33] N. I. Eisenberger and S. W. Cole, "Social neuroscience and health: neurophysiological mechanisms linking social ties with physical health," Nature Neuroscience, vol. 15, 2012.

[34] J. S. House, "Social isolation kills, but how and why?" Psychosomatic Medicine, vol. 63, 2001.

[35] M. Heinrichs, T. Baumgartner, C. Kirschbaum, and U. Ehlert, "Socia support and oxytocin interact to suppress cortisol and subjective responses to psychosocial stress," Biological Psychiatry, vol. 54, 2003.

[36] J. Holt-Lunstad, T. B. Smith, and J. B. Layton, "Social relationships and mortality risk: A meta-analytic review," PLoS Medicine, vol. 7 , e1000316.

[37] S. S. Dickerson and M. E. Kemeny, "Acute stressors and cortisol responses: a theoretical integration and synthesis of laboratory research," Psychologica Bulletin, vol. 130, pp. 355-391, 2010.

[38] E. F. Walker and D. Diforio, "Schizophrenia: A neural diathesis-stress model," Psychological Review, vol. 104, pp. 667-685, 1997.

[39] V. R. Winkel, N. C. Stefanis, and I. Myin-Germeys, "Psychosocial stress and psychosis, A review of the neurobiological mechanisms and the evidence for gene-stress interaction," Schizophrenia Bulletin, vol. 34, pp. 1095-1105, 2008.

[40] J. C. Pruessner, F. Champagne, M. J. Meaney, and A. Dagher, "Dopamine release in response to a psychological stress in humans and its relationship to early life maternal care: A positron emission tomography study using raclopride," Journal of Neuroscience, vol. 24, pp. 2825-2831, 2004.

[41] A. F. Arnsten, "Stress signalling pathways that impair prefrontal cortex structure and function," Nature Reviews Neuroscience, vol. 10, pp. 410-422, 2009

[42] R. M. Sapolsky, "Why stress is bad for your brain," Science, vol. 273, pp. 749-750, 1996.

[43] A. Meyer-Lindenberg and H. Tost, "Neural mechanisms of social risk for psychiatric disorders," Nature Neuroscience, vol. 15, pp. 663-668, 2012.

[44] C. Heim and E. B. Binder, "Current research trends in early life stress and depression: review of human studies on sensitive periods, gene-environment interactions, and epigenetics," Experimental Neurology, vol. 233, pp. 102-111, 2012.

[45] F. S. Chen, R. Kumsta, B. V. Dawans, M. Monakhov, R. P. Ebstein, and M. Heinrichs, "Common oxytocin receptor gene (OXTR) polymorphism and social support interact to reduce stress in humans," in Proc. the National Academy of Sciences of the United States of America, 2011, vol. 108, pp. 19937-19942.

[46] E. A .Hammock and L. J. Young, "Microsatellite instability generates diversity in brain and sociobehavioral traits," Science, vol. 308, pp. 1630-1634, 2005.

[47] Y. Rydin, A. Bleahu, M., Davies et al., "Shaping cities for health: Complexity and the planning of urban environments in the 21st century," Lancet, vol. 379, pp. 2079-2108, 2012.

[48] A. Abbott, "Stress and the city: Urban decay," Nature, vol. 490, pp. 162-164, 2012.

[49] A. S. Zigmond and R. P. Snaith, "The hospital anxiety and depression scale," Acta Psychiatr Scand, vol. 67, pp. 361-70, 1983.

[50] K. Glavin, L. Smith, and R. Sorum, Prevalence of Postpartum Depression in two Municipalities in Norway, Scand J Caring Sci., 2009.

[51] C. Heim and E. B. Binder, "Current research trends in early life stress and depression: Review of human studies on sensitive periods, gene-environment interactions, and epigenetics," Experimental Neurology, vol. 233, pp. 102-111, 2012.

[52] J. Peen, R. A. Schoevers, A. T. Beekman, and J. Dekker, "The current status of urbanrural differences in psychiatric disorders," Acta Psychiatrica Scandinavica, vol. 121, pp. 84-93, 2010.

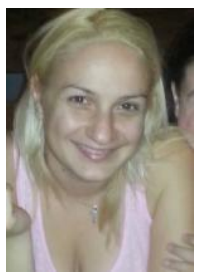

Koutsompou Violetta-Irene holds a bachelor's degree in English language/literature and psychology from the State University of New York, USA, a master's degree in English and comparative literature from the University of Indianapolis, USA, an accredited certificate in TEFL from Hellenic American University, a professional diploma in counseling psychology from City Unity College, Athens, Greece and a master of science degree in psychology from the University of East London, UK. She has attended seminars and specializes in psychoanalysis and Jungian psychology at the Carl Gustav Jung Institute, in Zurich. Ms Koutsompou has taught as an invited lecturer in colleges in Greece where she presented her thoughts and theory about children's literature and development and loss in every aspect of life. Her areas of interest and concentration are psychology of child development, children's literature and its impact on the cognitive and emotional development, depression, grief and loss, second language acquisition, postmodern literature, women's psychology and writings, book editing and writing. She has worked in private language institutions in Greece since 2005; she was interested and worked with children with special learning difficulties such as dyslexia, as well as with children with behavioral problems in the language classroom. She has presented her work in many conferences in Greece and abroad and in 2013 she was awarded a Certificate of Excellence for her research in postnatal depression from the committee of the 2nd psychology conference of City Unity College in Greece. She is a graduate member of the British Psychological Society, an Affiliate International member of the American Psychological Association, member of the TESOL Greece, of the IRED, etc 